\title{
TRENDS IN PERCEPTION OF PSYCHOSOCIAL SCHOOL ENVIRONMENT: HBSC STUDY 2002-2014 IN THE CZECH REPUBLIC
}

\author{
Jana Vašíčková', Tomáš Hollein', Erik Sigmund', Ferdinand Salonna1, Zuzana Boberová2 \\ ${ }^{1}$ Faculty of Physical Culture, Palacký University Olomouc, Olomouc, Czech Republic \\ ${ }^{2}$ Faculty of Arts, Pavol Jozef Šafárik University in Košice, Košice, Slovak Republic
}

\begin{abstract}
SUMMARY
Objective: School is a place where students spend most of their daytime hours. Previous studies indicate that the class climate significantly affects students in both positive and negative ways. The aim of our study is to describe the trends in the psychosocial school environment based on four surveyed years in the Czech Republic.

Methods: The trends in perception of school were assessed by the standardised self-reported HBSC questionnaire from data collected in 2002, 2006,2010 , and 2014 . The overall sample included 8,530 girls and 8,087 boys. Data was analysed separately by gender and three age categories 11,13 , and 15 years. Trends were calculated using descriptive categories and percentages. To identify factors influencing school likeness we used binominal logistic regression.

Results: Results showed that school satisfaction declines with age both in boys and girls in each of four surveyed periods. Students who do not feel a high level of support from the teacher are more prone to negative perceptions of school. School duties in both genders were perceived to be greater and more stressful in 2014 than in 2002.

Conclusions: Interventions to support the perception of psychosocial school environment via the educational system should, therefore, take the aforementioned variation into account.
\end{abstract}

Key words: school satisfaction, HBSC questionnaire, school environment, classmate relationship, teacher's support, school pressure

Address for correspondence: J. Vašičková, FTK UP Olomouc, trída Míru 111,771 11 Olomouc, Czech Rebublic. E-mail: jana.vasickova@upol.cz https://doi.org/10.21101/cejph.a4823

\section{INTRODUCTION}

School is one of the most frequently studied environments in which adolescents spend a substantial amount of time $(1$, 2). As a result, supportive school and classroom environments with positive classroom climates characterised by teacher's support and classmates' support should shape students' behaviour and conduct and also help them to acquire healthy habits (3). Social support, especially from teachers significantly enhanced students' happiness and thus lowered negative psychosomatic symptoms. On the other hand, an increasing degree of stress experience reduced student's happiness significantly (4). The classroom environment is created by physical factors (e.g., furniture, light, space design) and by psychosocial factors (e.g. the relationship between students and teachers). Mutual interaction among students and also between students and the teacher creates a classroom climate that is quite stable. On the other hand, a classroom atmosphere is very often unstable influenced by current situation (5).

Students' perceptions and experiences in a school setting influence the development of their self-esteem, self-perception, and health behaviour and in the future formation their well-being (6). School can sometimes be risky for future development of a student's health behaviour and also for motivation and engage- ment if the classmates and teacher are not kind and supportive (7). Those students who dislike school are likely to fail academically, can adopt unhealthy behaviour and face psychosomatic problems (8). Previous research illustrates that students who have positive association regarding school climate and their classmates are more motivated to learn and are more successful than those who are unsatisfied with school $(9,10)$. On the other hand, students who feel connected to school are less likely to skip school or be involved in fighting, bullying, and vandalism.

Thus, it is important to observe trends in likeness of school and classroom environment and related factors because changes in these trends can signal bullying perpetration and victimisation (11). From previous research it is evident that both bullies and victims report lower school attachment than non-involved peers (12). In addition, low academic achievement appeared in both perpetrators and victims (13-15).

Support from classmates and teachers would create a positive school climate. This climate would act as a positive resource to balance school demands and thus reduce school pressure. This balance would also reduce the likelihood of experiencing negative stress-related effects on health (3).

The main objective is to describe trends in students' perceptions of the psychosocial school environment in four surveyed years based on self-completed questionnaires administered in the 
classroom. An addition objective is to find the main factors that influence school satisfaction (liking or disliking school).

\section{MATERIALS AND METHODS}

Data from the survey was obtained in four years - 2002, 2006, 2010 and 2014 as part of the Health Behaviour in School-Aged Children (HBSC) study in the Czech Republic. The Health Behaviour in School-Aged Children study is a collaborative cross-national survey in coordination with the World Health Organisation (16). The HBSC protocol was followed each year in three age groups (11-, 13-, and 15-year-old children) (16-18).

After data adjustment regarding the age categories, 16,617 questionnaires were entered into the statistical analysis programme (SPSS v.22) (19). In order to assess the differences in age groups for the surveyed years, we controlled for gender by using non-parametric data analysis (chi-square and $\mathrm{r}$ - effect size coefficient). The proportion of data regarding age categories and number of respondents are presented in Table 1.

Measures were obtained from standardised self-reported questionnaires. We chose only questions regarding school environment and individual perceptions of classmate relationships (questions about individual perception of classmate relation- ships - 3 statements, school pressure, academic performance, and school satisfaction).

Due to the complexity of the analysis, most independent variables were categorised as dichotomous or trichotomous indicators to facilitate model interpretation. Dichotomous or trichotomous classification of all independent variables is somewhat rough, but such a classification is likely less prone to error. Details regarding survey items used, data reduction techniques and analytic variable specifications are presented in Table 2.

\section{RESULTS}

\section{School Satisfaction}

Significant differences were found in the trend data for boys regarding their school satisfaction (liking school). Figure 1 shows the decline in liking school by surveyed year regarding the age of boys (e.g. in 2002 15-year-old boys evaluated school as being less satisfying than 13-year-old boys did and 13-year-old boys had worse evaluations than 11-year-old boys). For every surveyed year the older boys showed a lower percentage of liking school. The worst situation was in 2002 when only $54.1 \%$ of 15 -year-old boys liked school.

Table 1. Basic description of dataset according to gender, age and the year of survey $(N=16,617)$

\begin{tabular}{|c|c|c|c|c|c|}
\hline & 2002 & 2006 & 2010 & 2014 & Total (\%) \\
\hline \multicolumn{6}{|l|}{ Girls } \\
\hline 11 years & 720 & 658 & 637 & 713 & $2,728(32.0)$ \\
\hline 13 years & 723 & 690 & 720 & 774 & $2,907(34.1)$ \\
\hline 15 years & 701 & 709 & 715 & 770 & $2,895(33.9)$ \\
\hline Total & 2,144 & 2,057 & 2,072 & 2,257 & $8,530(100.0)$ \\
\hline \multicolumn{6}{|l|}{ Boys } \\
\hline 11 years & 661 & 676 & 647 & 659 & $2,643(32.7)$ \\
\hline 13 years & 614 & 712 & 590 & 725 & $2,641(32.7)$ \\
\hline 15 years & 649 & 730 & 655 & 769 & $2,803(34.6)$ \\
\hline Total & 1,924 & 2,118 & 1,892 & 2,153 & $8,087(100.0)$ \\
\hline
\end{tabular}

Table 2. Description of analytic variables and their possible answers

\begin{tabular}{|l|l|l|}
\hline Analytic variable & Survey item(s) and original (response options) & Analytic variable levels \\
\hline \multirow{3}{*}{ School satisfaction } & $\begin{array}{l}\text { How do you feel about school at present? } \\
\text { (I like it a lot, I like it a bit, I don't like it very much, I don't like it at all) }\end{array}$ & $\begin{array}{l}\text { Like (Like a lot, like a bit) } \\
\text { Dislike (Don't like it very much, don't like it at all) }\end{array}$ \\
\hline \multirow{5}{*}{ Academic performance } & $\begin{array}{l}\text { In your opinion, what does your class teacher(s) think about your } \\
\text { classroom performance compared to your classmates? (Very good, } \\
\text { good, average, below average) }\end{array}$ & $\begin{array}{l}\text { Very good/good } \\
\text { Average } \\
\text { Below average }\end{array}$ \\
\hline & $\begin{array}{l}\text { The students in my classes enjoy being together. (Strongly disagree } \\
\text { to strongly agree, 1-5) }\end{array}$ & Positive (Strongly agree/agree) \\
\cline { 2 - 3 } & $\begin{array}{l}\text { Most of the students in my classes are kind and helpful. (Strongly } \\
\text { disagree to strongly agree, 1-5) }\end{array}$ & Neutral \\
\cline { 2 - 3 } & $\begin{array}{l}\text { Other students accept me as I am. (Strongly disagree to strongly } \\
\text { agree, 1-5) }\end{array}$ & Negative (Disagree/strongly disagree) \\
\hline School pressure & $\begin{array}{l}\text { How pressured do you feel by the school work? (Not at all, a little, } \\
\text { sometimes more, a lot) }\end{array}$ & $\begin{array}{l}\text { Negligibly (Not at all, a little) } \\
\text { Greatly (Sometimes more, a lot) }\end{array}$ \\
\hline
\end{tabular}


On the other hand, there was a slightly positive trend in age categories with regard to surveyed year. An exception for 11 and 13-year-old boys in 2010 was found. The biggest differences in trend data were found in 15-year-old boys where the "effect size" coefficient showed a small effect over the four-year period $\left(\chi^{2}=64.02 ; p<0.01 ; r=0.15\right)$. In this age category, the trend was increasing during the four surveyed years; this was in contrast to other age categories where in 2010 boys showed the highest percentage of school likeness. The difference for 11-year-old boys was significant $\left(\chi^{2}=16.73 ; \mathrm{p}<0.01 ; \mathrm{r}=0.08\right)$ but the effect size of the coefficient did not confirm the effect. The difference for 13-year-old boys was also significant $\left(\chi^{2}=31.24\right.$; $p<0.01$; $\mathrm{r}=0.11$ ) but a result similar to younger boys was found - namely, a non-significant coefficient of effect size.

Data obtained from girls showed significant differences only in 13-year-olds $\left(\chi^{2}=21.52 ; \mathrm{p}<0.01 ; \mathrm{r}=0.09\right)$ and 15 -year-olds $\left(\chi^{2}=27.99 ; \mathrm{p}<0.01 ; \mathrm{r}=0.10\right)$ regarding the question about liking being in school (Fig. 1). Similar to boys, girls showed a decline of liking to be in school with age. For example, if we compare data from 2002, 15-year-old girls had worse evaluations of school satisfaction than 13-year-old girls and 13-year-old girls had worse evaluation of school satisfaction than 11-year-old girls. In 2002, $82.1 \%$ of 11 -year old girls liked to be in school while in 15 -yearold girls there was a $20 \%$ decline (only $62.4 \%$ ).

We were also interested in factors that influenced "liking to be in school" in both genders. Thus, we used binominal logistic regression with the dependent variable "like to be in school" (like/dislike) and independent variables including academic achievement, school stress, and 3 questions regarding classmate relationship.

Binominal logistic regression (dependent variable $=$ likeness of school) showed that boys who were pressured by school work had almost four times lower chance of liking school $(\mathrm{OR}=0.28$; CI 0.23-0.33) and those whose teacher thought their performance was below average had almost a five times lower chance of liking school ( $\mathrm{OR}=0.22$; CI 0.17-0.28). In boys, those who perceived classmate relationships to be negative had a lower chance of "liking school" (being together: $\mathrm{OR}=0.73$; CI 0.59-0.89; students are kind and helpful: $\mathrm{OR}=0.39$; CI $0.33-0.46$; student's acceptation: $\mathrm{OR}=0.54$; CI $0.45-0.64)$.

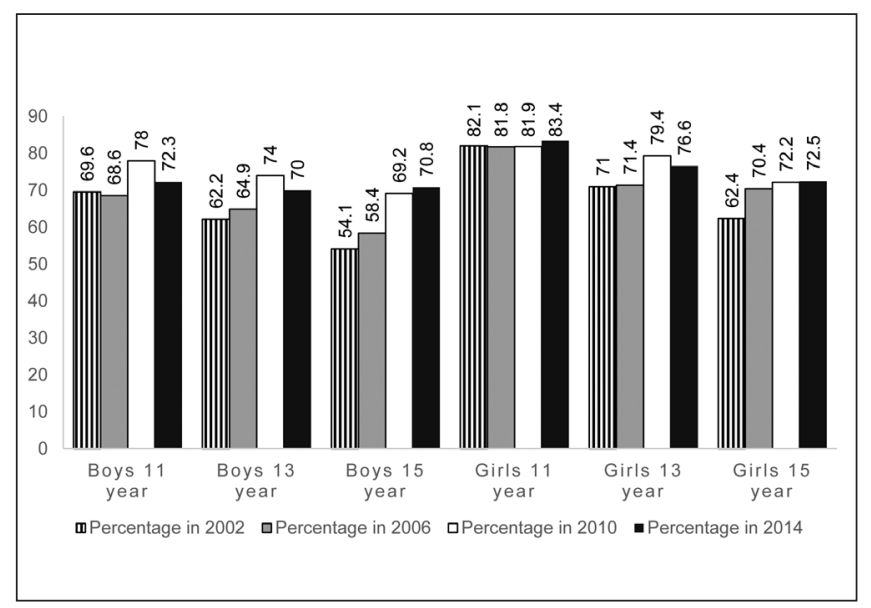

Fig. 1. Trends in positive answers to the statement "Like to be in school" in boys and girls by age and the year of HBSC survey.
In girls, we found out an almost five times lower chance of "liking school" for those whose teacher thought that their performance was below average $(\mathrm{OR}=0.2$; CI $0.15-0.26)$. In addition, extraordinary stress from school work $(\mathrm{OR}=0.37$; CI $0.31-0.45$ ) and negative classmate relationship in girls (being together: $\mathrm{OR}=0.45$; $\mathrm{CI} 0.38-0.55$; students are kind and helpful: $\mathrm{OR}=0.38$; CI $0.32-0.46$; student's acceptation: $\mathrm{OR}=0.48$; CI $0.40-0.57$ ) were predictors of a low chance of "liking school."

\section{Trends in Academic Performance}

Academic performance was assessed using one item: "In your opinion, what does your class teacher(s) think about your school performance compared to your classmates?" We used a trichotomised scale (11) for analysis (very good/good; average; below average). No statistical differences were found in girls with respect to the three age groups over the surveyed years. The percentage of positive teacher evaluations differed from $52.9 \%$ to $61.5 \%$. However, in boys we found a statistical difference in 13 -year-old boys $\left(\chi^{2}=15.67 ; \mathrm{p}<0.01 ; \mathrm{r}=0.08\right)$ where in 2002 , $48.2 \%$ of 13 -year old boys felt the teacher had good opinion of them $(52.1 \%$ in $2006,56.5 \%$ in 2010$)$; the lowest percentage was found in 2014 (46.6\%).

\section{Trends in Classmate Relationships}

The relationship to one's classmates was measured using three items assessing enjoyment of classmate companionship, kindness and helpfulness of classmates, and classmate acceptance of the respondent. First, there were statistical differences in boys for the statement "Students like being together" in a class (11-year-old: $\chi^{2}=22.51 ; \mathrm{p}<0.01 ; \mathrm{r}=0.09 ; 13$-years-old: $\chi^{2}=41.65 ; \mathrm{p}<0.01$; $\mathrm{r}=0.13$; 15 -year-old: $\left.\chi^{2}=56.44 ; \mathrm{p}<0.01 ; \mathrm{r}=0.14\right)$; statistical differences were also found for girls (11-year-old: $\chi^{2}=20.69 ; \mathrm{p}<0.01$; $\mathrm{r}=0.09 ; 13$-year-old: $\chi^{2}=61.00 ; \mathrm{p}<0.01 ; \mathrm{r}=0.15 ; 15$-year-old: $\chi^{2}=75.28 ; \mathrm{p}<0.01 ; \mathrm{r}=0.16$ ) (Fig. 2). We observed a declining trend in boys and girls in 2002 and in girls in 2006 regarding age. A slowly growing trend was noticed in boys in 2014 with regard to age. The most positive answers about students liking being together was observed in all age groups and both genders

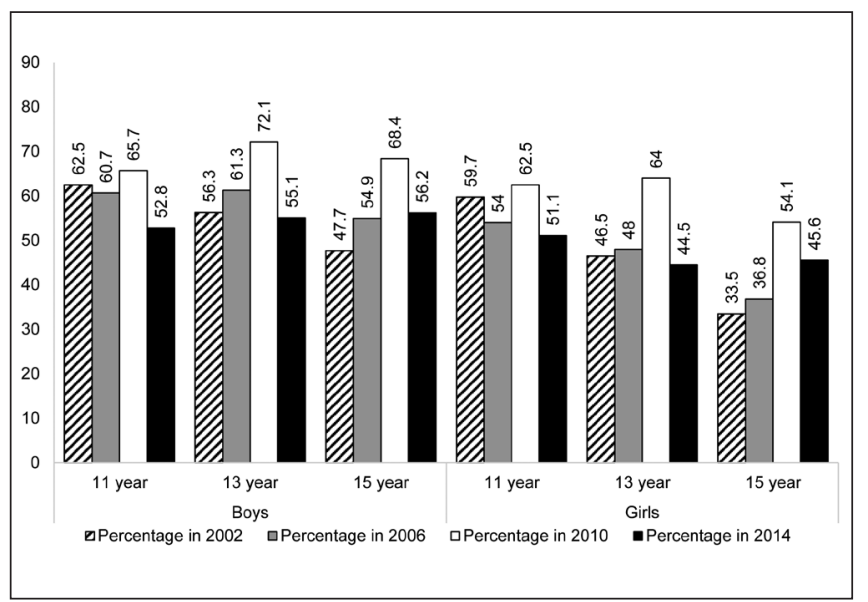

Fig. 2. Trends in positive answers to the statement "Students like being together" in boys and girls regarding age and the year of the HBSC survey. 
in 2010. The lowest percentage of positive answer was reported by 15 -year-old girls in 2002 .

Another statement that was evaluated regarding relationship with classmates was "Most of the students in my classes are kind and helpful." Kindness and helpfulness of classmate was assessed with single item inquiring how much the respondent agreed with the statement; responses were recoded to be consistent with previous research (20) as "positive" ("strongly agree" and "agree"), "neutral" or "negative" ("disagree" and "strongly disagree"). Statistical differences were found in 13-year-old boys $\left(\chi^{2}=23.82\right.$; $\mathrm{p}<0.01 ; \mathrm{r}=0.10)$ and 15 -year-old boys $\left(\chi^{2}=73.93 ; \mathrm{p}<0.01\right.$; $\mathrm{r}=0.16)$. The percentage of positive expressions in boys varied from $34.6 \%$ to $57.1 \%$ (Fig. 3). In girls, statistical differences were found for all age groups (11-year-old: $\chi^{2}=11.07 ; \mathrm{p}<0.01 ; \mathrm{r}=0.06$; 13-year-old: $\chi^{2}=40.39 ; \mathrm{p}<0.01 ; \mathrm{r}=0.12 ; 15$-year-old: $\chi^{2}=78.37$; $\mathrm{p}<0.01 ; \mathrm{r}=0.17)$. The percentage of positive expression in girls varied from $33.5 \%$ to $63.5 \%$.

Finally, the last statement regarding classmate relationships was "Other students accept me as I am." Classmate acceptance of the respondent was coded as "positive," "neutral," and "negative." Statistical differences were found for girls of all age groups (11-year-old: $\chi^{2}=16.45 ; \mathrm{p}<0.01 ; \mathrm{r}=0.08 ; 13$-year-old: $\chi^{2}=13.72$; $\mathrm{p}<0.01 ; \mathrm{r}=0.07 ; 15$-year-old: $\left.\chi^{2}=15.58 ; \mathrm{p}<0.01 ; \mathrm{r}=0.07\right)$; no statistical differences were found for boys. The percentage of positive answers ranged from $62.6 \%$ to $76.2 \%$ (Fig. 4). In boys, positive answers were more consistent ranging from $69.3 \%$ to $78.1 \%$.

\section{Trends in School Pressure}

The stress students faced in school also influenced liking school. This was expressed by the statement "How pressured do you feel by the school work?" with possible answers that were coded into "negligibly" ("not at all" and "a little"), and "greatly" ("sometimes more" and "a lot"). Among the group of boys, we found statistical difference only in 11-year-olds $\left(\chi^{2}=19.97\right.$; $\mathrm{p}<0.01 ; \mathrm{r}=0.09$ ) with a range from $72.3 \%$ to $77.7 \%$ of those not being stressed (Fig. 5). Girls appear to be more vulnerable to stress as we found statistical differences in all surveyed age groups (11-year-old: $\chi^{2}=12.76 ; \mathrm{p}<0.01 ; \mathrm{r}=0.07 ; 13$-year-old: $\chi^{2}=10.99 ; \mathrm{p}<0.05 ; \mathrm{r}=0.06 ; 15$-year-old: $\chi^{2}=37.56 ; \mathrm{p}<0.01 ; \mathrm{r}=$

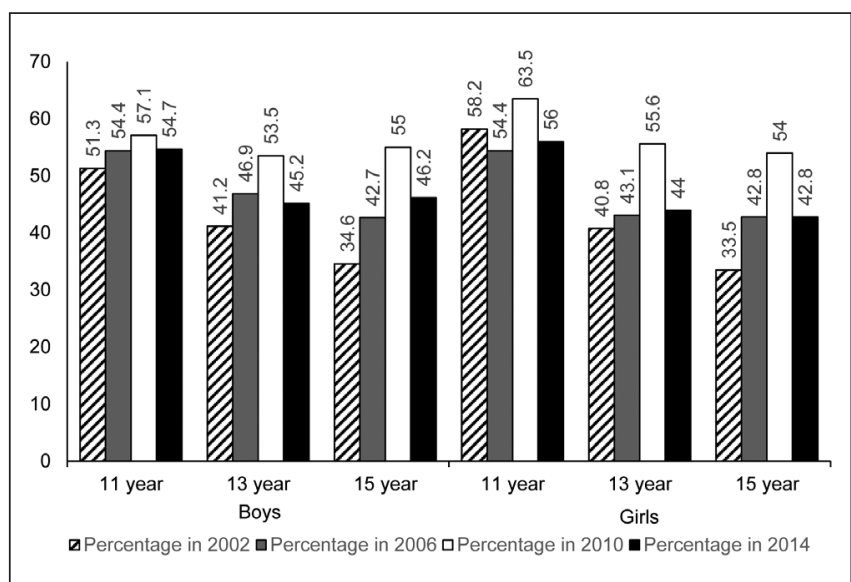

Fig. 3. Trends in positive answers to the statement "Most of the students in my classes are kind and helpful" in boys and girls regarding age and the year of the HBSC survey.

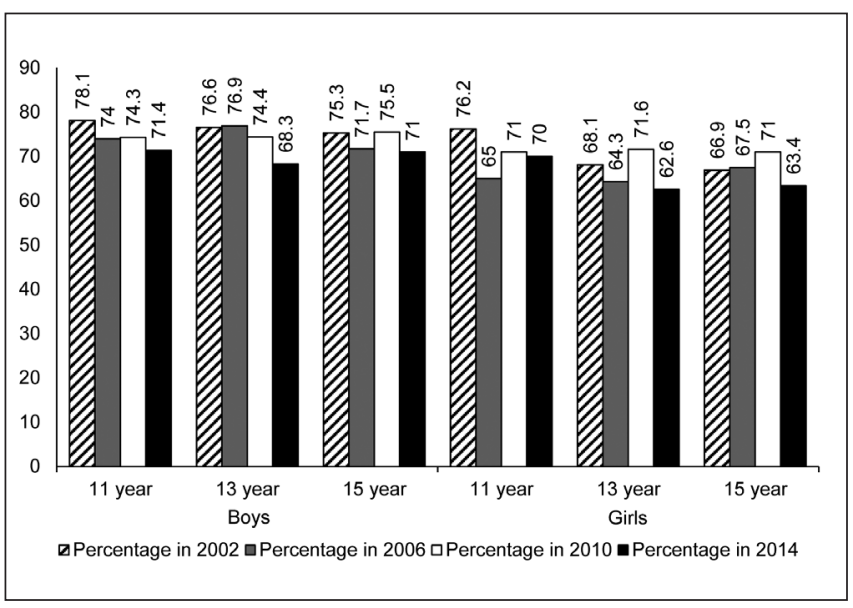

Fig. 4. Trends in positive answers to the statement "Other students accept me as I am" in boys and girls regarding age and the year of the HBSC survey.

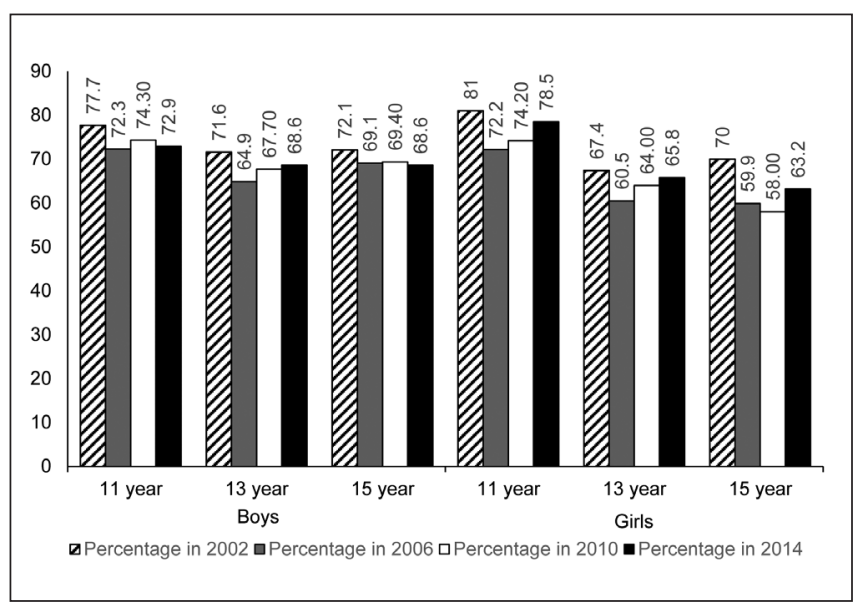

Fig. 5. Trends in negative answers (not at all and a little) to the statement "How pressured do you feel by the school work?" in boys and girls regarding age and the year of the HBSC survey.

$0.11)$. Not being stressed by school work was expressed by $58 \%$ to $81 \%$ of girls. Unfortunately, a negative trend was observed in those who were greatly stressed by school duties; this increased in boys from $6.1 \%$ in 2002 to $13.4 \%$ in 2014 and in girls from $3.5 \%$ in 2002 to $12.4 \%$ in 2014 .

\section{DISCUSSION}

The aim of the article was to describe trends in students' perceptions of psychosocial school environment that consisted of liking school, teachers support based on school performance, classroom climate based on classmate relationships (like to be together, kindness and helpfulness, acceptation) and schoolwork demand.

The biggest popularity of school was found among 11-year-old girls and was very balanced (81.8-83.4\% of girls liked school). The percentages of positive answers were consistently the lowest in 15-year-old boys compared to younger age groups. However, with each passing survey year positive trend in liking school was observed in 15-year old boys. Generally, boys do not like school 
as much as girls (66.8\% vs. $74.8 \%)$ and older students, regardless of gender, are less satisfied with school (73.3\% of 11-year-old; $70.7 \%$ of 13 -year-old; $66.1 \%$ of 15 -year-old students) (8). This is in agreement with some foreign studies based on HBSC data (21-23). Lower satisfaction with school in older adolescents is probably influenced by the specificity of certain developmental periods mainly due to a change in thinking, emotional development and physical appearance (24). Older students perceive school environment more negatively and are critical of democracy and teachers' support because they try to break out of the authoritative dependency and are able to consider quality and usefulness of instruction programme. This is in agreement with another study (25) in which the authors reported that being treated unfairly by teachers was more often reported by 13-18 year olds compared to younger children (10-12y, grade 3-6). In addition, success can influence school satisfaction because one study claimed that less successful students had a worse relationship toward school (26).

The biggest influence on school attachment was teacher's support, regardless of students' gender and the level of school pressure. Student's satisfaction with school depends on personal characteristics such as sociability but also social characteristics of family, school environment and a good relationship with the teacher (8).

Variable "academic performance" can be also understood as teacher's support. There was no other question of the same version over all four surveyed years studying teacher's activity, only student's perception of teacher's thinking was asked. The general finding is that girls more so than boys, thought that teachers had more positive opinions of their performance. Boys perceived teachers to be more critical of them; among boys who liked school, $7.4 \%$ (compared to $5.2 \%$ of girls) thought that the teacher regarded their performance to be below average. In all age groups and also within international comparisons, in most countries girls are more satisfied in school (23), are teacher's favourites, are more conscientious and have, on average, better results in elementary schools than do boys (21). Social support from school teachers has a strong influence and can also significantly enhance happiness; happier students might report particular psychosomatic symptoms less often (4). One study indicated that, on the other hand, perceived teacher unfairness can be a significant predictor of frequent headaches during adolescence, and this association is consistent across countries (27).

Feeling that students accept each other was reported to be very positive regardless of gender, age and surveyed years. Only $9.4 \%$ of students disagreed with the statement "other students accept me as I am" (8.6\% of boys and $10.2 \%$ of girls). A similar level of disagreement was also found for the statement "students like being together:" $8.5 \%$ of them perceived that the climate in the classroom was not sympathetic. On the other hand, a big discrepancy was observed in the item "students are kind and helpful," where $17.5 \%$ of students did not agree with the statement. For all items from the classroom relationship variable, girls were more negative in their expression than boys.

Regardless of age and gender, the biggest differences in percentage were observed in the answers to the statement "students are kind and helpful." Perception of what it means to be kind and helpful differs and can be affected by, for example, the family values. Family is the primary educational institution that shapes and influences children and also shares common values.
A significant percentage of 11-year-old boys perceived some or a lot of pressure by school duties. In addition, for girls, significant differences were found in all age group. Eleven-year-old children face increased demands in school; some of them in this age have to decide what school to choose for their future studies. They can change school according to their academic achievement or interest and thus they first undergo testing of their school knowledge. This new situation can put more pressure on them and is probably reflected in their answers.

The strength of the study is in its consistency because this survey has been organised by one group of people since 2002 following consistent application of procedures and protocols. The HBSC team have established a good system of surveyors and unique methodology to collect data. The large national representative sample allowed for trend analysis separately for both genders and three age categories. On the other hand, the HBSC team collects data on international bases (in 40 countries) and to be comparable unique questionnaire is elaborated each fourth year. Each country translates this particular questionnaire to their national language (28). Each variable has to make sense across different cultures and school systems. Because of this, questions have to be generally applicable to fit different situations and cultures; this can be viewed as a disadvantage for a study in single country.

\section{CONCLUSION}

The aim of the study was to describe the trends in perception of psychosocial school environment based on subjective answers using four years of the international HBSC survey. Another target was to find out the main factors that influence the degree to which students like school (satisfaction). Satisfaction with school declined with age both in boys and girls during the four surveyed periods. Factors that can negatively affect school satisfaction include low teacher's support perceived by students, high pressure regarding school duties and negative classmate relationships. Boys are more negative about teacher's support through academic achievement than are girls. Almost two times the percentage of students disagreed with the fact that students are kind and helpful compared to two other variables that defined classmate relationship. For both genders, school duties are perceived to be greater and more stressful in 2014 than in 2002. To conclude, slightly increasing trend in liking to be in school during four studied periods was found out in both genders, however, girls like to be in school more than boys. Thus, the interventions to support the perception of psychosocial school environment (e.g. activities that unite children in their classroom as some cooperating activities; working on some educational projects in small teams or teachers should give reason for amount of school work and more motivate children) via the educational system should, therefore, consider the aforementioned variation. These findings could serve to researchers for comparison not only on national but also international level.

\section{Acknowledgement}

This paper was supported by the research grant of the Czech Science Foundation "Trends in behaviour among Czech adolescents in the context of school and family environment: HBSC study between the years 2002-2018," reg. No. GA17-12579S 


\section{Conflict of Interests}

None declared

\section{REFERENCES}

1. Fox KR. Tackling obesity in children through physical activity: a perspective from the United Kingdom. Quest. 2004;56(1):28-40.

2. Sigmund E, Sigmundová D. School-related physical activity, lifestyle and obesity in children. Olomouc: Palacký University Olomouc; 2014.

3. García-Moya I, Rivera F, Moreno C. School context and health in adolescence: the role of sense of coherence. Scand J Psychol. 2013 Jun;54(3):243-9.

4. Natvig GK, Albrektsen G, Qvarnstrøm U. Associations between psychosocial factors and happiness among school adolescents. Int J Nurs Pract. 2003 Jun;9(3):166-75.

5. Průcha J. Classroom climate in Czech schools: comparing the findings of empirical studies. Stud Paedagog. 2002;50(U7):63-75. (In Czech.)

6. Seiffge-Krenke I, Aunola K, Nurmi JE. Changes in stress perception and coping during adolescence: the role of situational and personal factors. Child Dev. 2009 Jan-Feb;80(1):259-79.

7. Ryan AM, Patrick H. The classroom social environment and changes in adolescents' motivation and engagement during middle school. Am Educ Res J. 2001;38(2):437-60.

8. Samdal O, Nutbeam D, Wold B, Kannas L. Achieving health and educational goals through schools - a study of the importance of the school climate and the students' satisfaction with school. Health Educ Res. 1998;13(3):383-97.

9. Bond L, Butler H, Thomas L, Carlin J, Glover S, Bowes G, et al. Social and school connectedness in early secondary school as predictors of late teenage substance use, mental health, and academic outcomes. J Adolesc Health. 2007 Apr;40(4):357.e9-18.

10. Blum RW. A case for school connectedness. Educ Leadersh. 2005;62(7):16-20.

11. Spriggs AL, Iannotti RJ, Nansel TR, Haynie DL. Adolescent bullying involvement and perceived family, peer and school relations: commonalities and differences across race/ethnicity. J Adolesc Health. 2007 Sep;41(3):283-93.

12. Haynie DL, Nansel T, Eitel P, Crump AD, Saylor K, Yu K, et al. Bullies, victims, and bully/victims: Distinct groups of at-risk youth. J Early Adolesc. 2001;21(1):29-49.

13. Nansel TR, Overpeck M, Pilla RS, Ruan WJ, Simons-Morton B, Scheidt P. Bullying behaviors among US youth: prevalence and association with psychosocial adjustment. JAMA. 2001 Apr 25;285(16):2094-100.

14. Bishop JH, Bishop M, Bishop M, Gelbwasser L, Green S, Peterson E, et al. Why we harass nerds and freaks: a formal theory of student culture and norms. J Sch Health. 2004 Sep;74(7):235-51.
15. Eisenberg ME, Neumark-Sztainer D, Perry CL. Peer harassment, school connectedness, and academic achievement. J Sch Health. 2003 Oct:73(8):311-6

16. Roberts C, Freeman J, Samdal O, Schnohr CW, de Looze ME, Nic Gabhainn S, et al.; International HBSC Study Group. The Health Behaviour in School-aged Children (HBSC) study: methodological developments and current tensions. Int J Public Health. 2009 Sep;54 Suppl 2:140-50.

17. Currie C, Nic Gabhainn S, Godeau E; International HBSC Network Coordinating Committee. The Health Behaviour in School-aged Children: WHO Collaborative Cross-National (HBSC) study: origins, concept, history and development 1982-2008. Int J Public Health. 2009 Sep;54 Suppl 2:131-9.

18. Roberts C, Currie C, Samdal O, Currie D, Smith R, Maes L. Measuring the health and health behaviours of adolescents through cross-national survey research: Recent developments in the Health Behaviour in Schoolaged Children (HBSC) study. J Pub Health. 2007;15(3):179-86.

19. IBM Corp. IBM SPSS Statistics for Windows, Version 22.0. Armonk: IBM Corp; 2013.

20. Haapasalo I, Välimaa R, Kannas L. How comprehensive school students perceive their psychosocial school environment. Scand J Educ Res. 2010;54(2):133-50.

21. Ding C, Hall A. Gender, ethnicity, and grade differences in perceptions of school experiences among adolescents. Stud Educ Eval. 2007;33(2):15974.

22. Borup I, Holstein BE. Does poor school satisfaction inhibit positive outcome of health promotion at school? A cross-sectional study of schoolchildren's response to health dialogues with school health nurses. J Adolesc Health. 2006 Jun;38(6):758-60.

23. Currie C, Gabhainn SN, Godeau E, Roberts C, Smith R, Currie D, et al., editors. Inequalities in young people's health: HBSC international report from the 2005/2006 survey. Copenhagen: WHO Regional Office for Europe; 2008.

24. Vágnerová M. Developmental psychology I. Childhood and maturation. Prague: Karolinum; 2005. (In Czech.)

25. Hjern A, Alfven G, Ostberg V. School stressors, psychological complaints and psychosomatic pain. Acta Paediatr. 2008 Jan;97(1):112-7.

26. Kalman M, Vašíčková J, editors. Health and lifestyle of children and pupils. Olomouc: Palacký University Olomouc; 2013. (In Czech.)

27. Lenzi M, Vieno A, De Vogli R, Santinello M, Ottova V, Baška T, et al. Perceived teacher unfairness and headache in adolescence: a crossnational comparison. Int J Public Health. 2013;58(2):227-35.

28. Cull A, Sprangers M, Bjordal K, Aaronson N, West K, Bottomlex A. EORTC quality of life group: translation procedure. Brussels: EORTC; 2002.

Received January 19, 2017 Accepted in revised form June 1, 2017 